\title{
Recurrent synovitis of hip and MEFV gene related arthritis in children
}

\author{
Farhad Salehzadeh and Mehrdad Mirzarahimi* (D)
}

\begin{abstract}
Background: Recurrent and relapsing arthritis has been proposed to describe a group of arthritis with recurring and periodic nature, in which the joints are intermittently involved.

This study reports three non-FMF patients with heterozygous MEFV gene mutations and an extraordinary arthritis as a recurrent synovitis of hip (RSH).

Methods: During 16-years from 2003 to 2019 at pediatric rheumatologic clinic among 195 recorded files with chronic oligoarthritis, 3 patients with diagnosis of recurrent synovitis of hip (RSH) were reviewed thoroughly. Peripheral blood was collected from patients and the samples were screened for the 12 common MEFV gene pathogenic variants.
\end{abstract}

Results: This study included three patients, two female and one male with relapsing idiopathic arthritis that has been located on hip joints as a sole manifestation and pathologic findings of MEFV mutations as follow: A744S, V726A, and R761H.

Conclusion: On the basis of possible role of MEFV gene in different rheumatic disease, MEFV gene related arthritis may be considered as a background of RSH particularly in Mediterranean area.

Keywords: FMF, MEFV gene, Recurrent synovitis of hip

\section{Background}

Recurrent arthritis has been proposed to describe a group of arthritis that has periodic nature, in which the joints are intermittently involved. It may result from genetic, infectious or hereditary and/or acquired background [1]. These include arthropathy of familial Mediterranean fever (FMF) particularly in Mediterranean area; inflammatory bowel disease (IBD) - related arthritis; crystalline arthropathies, such as gout; Whipple's disease; Behcet's syndrome; relapsing polychondritis and intermittent hydrarthrosis [2].

Familial Mediterranean fever (FMF) is an autosomal recessive inherited auto inflammatory disorder. It affecting mainly Mediterranean people especially Jews, Armenians,

\footnotetext{
* Correspondence: mmirzarahimi@arums.ac.ir

Pediatric Rheumatology, Pediatric Department, Bouali Children's Hospital, Ardabil University of Medical Sciences (ARUMS), Ardabil, Iran
}

Arabs, and Turks, however; it is now being recognized in other populations, including Iranian, Italians and Greeks.

The clinical manifestations of FMF are characterized by recurrent periods of fever, associated with serositis, erysipelas-like erythema and arthritis [3].

A gene for FMF (MEFV) has been identified on the short arm of chromosome 16, and more than 330 mutations in this gene have been demonstrated in patients with FMF [4].

Arthritis is the presenting finding of FMF in some patients, and sometimes it remains as the major manifestation of the disorder [5].

The frequency of arthritis in FMF has been reported to range $40 \%$ and or more in different ethnic groups [6]. The most common type of arthritis is large joints selflimited, recurrent, and short lived acute inflammation of the lower extremities [5]. 
This study reports three non-FMF pediatric patients with heterozygous $M E F V$ mutations and an extraordinary arthritis as a recurrent idiopathic and intermittent (left and right) synovitis of hip ( $\mathrm{RSH}$ ), that is not typical for FMF arthritis and known rheumatic disease and discusses about FMF related arthritis and different rheumatic disease that has been affected by $M E F V$ gene mutations.

\section{Material and methods}

\section{Patients}

During 16-years from 2003 to 2019 at pediatric rheumatologic clinic among 195 recorded files with chronic oligoarthritis, three patients with diagnosis of idiopathic $\mathrm{RSH}$ were reviewed thoroughly and twelve common $M E F V$ gene mutations were analyzed to evaluate the role of this mutation as a background of this entity.

Patients had negative histories of FMF manifestations and familial history of FMF. JIA, gout, psoriasis, IBD, SLE, celiac and infectious causes such as brucellosis and some especial disorders such as Ehlers Danlos and joint hypermobility; post-infectious arthritis, pain amplification syndromes and osteochondrosis and palindromic rheumatisim were excluded.

Tel-Hashomer criteria have been used to diagnosis of FMF. None of the patients and their first degree families had FMF related symptoms. Arthritis had been confirmed by imaging including MRI and or ultrasound further than laboratory tests. Patients had taken treatment in short course such as NSAID and Hydoxychloroquine (HCQ) intermittently as DMARDS with suspicion of unclassified and atypical JIA.

The study is complaint with the Helsinki Declaration and was approved by the local Ethics Committee under number (IR.ARUMS.- REC.1396.95). Informed consent was obtained from all the participants, and/or their parents.

\section{MEFV gene mutation analysis}

Peripheral blood was collected from patients and the samples were screened for the 12 common pathogenic variants (E148Q, P369S, F479 L, I692del, M680I (G/C), M680I (G/A), M694 V, M694I, K695R, V726A, A 744S, R $761 \mathrm{H}$ ) by an RDB assay (FMF Strip Assay, Vienna lab, Vienna, Austria) according to manufacturer's instructions, from fresh blood sampling simultaneously at genetic lab center of the hospital.

\section{Results}

This study included three patients with relapsing and intermittent (right and left) arthritis that has been located on hip joint as a sole manifestation with diagnosis of recurrent synovitis of hip (RSH). The mean attacks was three episodes in year and mean follow up of patients was at least 5 years.

All data of patients and their findings and demographic characteristics are presented in Table 1.

\section{Discussion}

Articular involvement is one of the most common and significant features of FMF. Arthritis usually occurs during recurrences, which can be short-term and selflimiting in nature. It is usually presented as monoarthritis of the lower extremity in large joints. Sometimes arthritis is one of the first symptoms of FMF, and occasionally it is the only episodic symptom of disease in FMF patients [7].

That is usually associated with fever, local redness, swelling and tenderness and positive family history of FMF, MEFV mutations analysis, and favorable response to colchicine [5]. Meanwhile 5\% of patients have chronic and protracted arthritis, usually of the hips or knees, with symptoms lasting a few months [7].

Chronic involvement of the hip is usually seen as repeated articular or protracted attacks in association with other systemic symptoms; however, chronic osteoarthritis of the hip joint can occur in adult patients without a history of attack at the affected joint [8].

Heller wrote the first comprehensive study about the arthritis in FMF patients, although his work confined to

Table 1 Patient's findings and manifestations

\begin{tabular}{|c|c|c|c|}
\hline Data & Patient 1 & Patient2 & Patient3 \\
\hline Sex & female & male & female \\
\hline Age at diagnosis & $3.5 \mathrm{yr}$ & $4 y r$ & $4.5 \mathrm{yr}$ \\
\hline Duration of follow-up (years) & $4 \mathrm{yr}$ & $5 \mathrm{yr}$ & $7 y r$ \\
\hline Number of episodes per year & $3-4$ & 3 & $3-4$ \\
\hline Attack intervals (mean) month & 3 to $4 \mathrm{mo}$ & $3 \mathrm{mo}$ & 3to $4 \mathrm{mo}$ \\
\hline Systemic symptoms during attacks & Low grade fever & moderate fever & Low grade fever \\
\hline Morning stiffness during attacks & No & No & No \\
\hline MEFV Mutations & A744S & V726A & $\mathrm{R} 761 \mathrm{H}$ \\
\hline Average duration of episodes & 3 days & 3-4 days & 5 days \\
\hline Joint /Right and left & $\begin{array}{l}\operatorname{Hip}(R / L) \\
\text { intermittently }\end{array}$ & $\begin{array}{l}\operatorname{Hip}(R / L) \\
\text { intermittently }\end{array}$ & $\begin{array}{l}\operatorname{Hip}(R / L) \\
\text { intermittently }\end{array}$ \\
\hline
\end{tabular}


adult patients, he analyzed the clinical, roentgenologic, and histologic features of the articular manifestations of FMF [9].

Eldar studied arthritis in 124 children with welldocumented familial Mediterranean fever (FMF), none of this group had arthritis before FMF symptoms, 75\% of the patients being under 10 years of age.

Arthritis was noted in the lower extremities 122 (98\%), upper extremities17 (14\%), and small joints of the hands and feet, 15 (12\%).He report three patients with atypical arthritis involving temporomandibular, sacroiliac, and sternoclavicular joints [5]. There was not any patient with exceptional hip involvement and as a sole manifestation of FMF.

Recent findings have shown that $M E F V$ gene is associated with other clinical and rheumatologic conditions. Screening of $M E F V$ mutations in different rheumatic diseases showed its effective role in these patients with arthritis other than FMF [10].

Several case reports and cohorts suggest an association between FMF and certain inflammatory disorders, such as rheumatoid arthritis [11], JIA [12] systemic onset JIA [13], seronegative spondyloarthropathy [14], HenochSchönlein purpura [15], polyarteritis nodosa [16], Behçet's disease (BD) [17], and Crohn disease [18].

It was shown that $M E F V$ mutations in patients with RA were associated with more severe diseases [11]. Furthermore, in Chinese and Indian patients with secondary amyloidosis, the prevalence of p.E148Q mutation was significantly higher than controls [19].

The allele frequencies of $M E F V$ mutations were found to be $19.27 \%$, in Turkish children with juvenile idiopathic arthritis which was higher than the general population [12].

Enthesopathy and sacroiliitis occur in some FMF patients, and up to $7.5 \%$ of FMF patients are simultaneously diagnosed with Ankylosing Spondyloarthropathy (AS) [20].

Gülhan's study showed that certain $M E F V$ mutations may be acting as susceptibility factors for enthesitis related arthritis (ERA). The presence of two patients with homozygous $M 694 \mathrm{~V}$ mutations while they lacked other clinical features of FMF at diagnosis of their JIA, also suggests that ERA should be considered in FMF patients [21].

It is a general consensus that spondyloarthropathy in FMF patients is negative for HLA-B27 whilst M694V might be a risk factor for AS [14].

$M E F V$ mutations are associated with "subclinical inflammation"; it has been showed by Tunca et al. [22] that, patients who were heterozygous for $M E F V$ mutations have increased blood levels of inflammatory markers.

Chetrit reports which defined patients with $M E F V$-related non-FMF entities [10], regarding the $M E F V$ gene and its link to such clinical phenotypes may lead to the existence of additional clinical presentations within the auto inflammatory diseases [23].
Furthermore, these $M E F V$ gene mutation-associated syndromes will justify a therapeutic trial with colchicine as a main or adjacent drug [10].

These patients diagnosed as idiopathic RSH with relapsing and recurrent arthritis of hip showed $M E F V$ gene mutations that include $\mathrm{R} 761 \mathrm{H}, \mathrm{V} 726 \mathrm{~A}$, and $\mathrm{A} 744 \mathrm{~S}$ in heterozygote form which are not normal variants of healthy people in this area. The most frequent variants among normal and healthy population are E148Q (18.3\%), followed by P369S (3.1\%), V726A (2.2\%), A744S (1.3\%), respectively [24].

Otherwise, in FMF patients of this area followings mutations are the most common variants alleles M694V (20.9\%), V726A (12.7\%), E148Q (10.7\%), M680I (10.3\%), M694I (2.1\%) [3].

Although transient synovitis of the hip is a common disorder in children, chronic and RSH is a very rare condition. The presence of $M E F V$ mutations in patients with RSH and its specific pattern, emphasis the potential role of this gene as a pathogenic background in this condition.

On the basis of possible role of $M E F V$ gene in different rheumatic disease RSH could be considered as a $M E F V$ gene related arthritis.

Although the outcome of children with one $M E F V$ mutation with lack of FMF symptoms continues to be a challenge particularly in pathogenic $M E F V$ mutation, periodic clinical visits is recommended during follow up of patients [25].

It is possible that these patients develop FMF related symptoms during their third and or more decades. If it occurs we will confront with a new dilemma; whether RSH is the first presentation of FMF related arthropathy, although it has not been reported up to now, and or it is a separate entity and co-existed with FMF. Because of the limited number of patients in this study a large sample size will be required to confirm this finding, however; $\mathrm{RSH}$ is not a common condition in children.

\section{Conclusion}

In our opinion, an idiopathic relapsing periodic arthritis in children with exclusively hip involvement (RSH) is a $M E F V$ gene related arthropathy.

\section{Abbreviations \\ ERA: Entesithis related arthritis; FMF: Familial Mediterranean fever; JIA: Juvenile Idiopathic Arthritis; MEFV: Mediterranean fever Gene; PR: Palindromic Rheumatism; RSH: Recurrent Synovitis of Hip}

\section{Acknowledgements}

None.

Authors' contributions

FS: carried out the management and diagnosis of patients. MM. Participated in the design of the study and performed the draft of manuscript. All authors read and approved the final manuscript. 


\section{Funding}

There is not any funding in this study.

\section{Availability of data and materials}

Please contact first author (Salehzadeh F.) for data request.

\section{Ethics approval and consent to participate}

This article does not contain any studies with human participants or animals performed by any of the authors.

The study is complaint with the Helsinki Declaration and was approved by the local Ethics Committee under number (IR.ARUMS.REC.1396.95). Informed consent was obtained from all parents individual participants included in the study.

\section{Consent for publication}

Not applicable.

\section{Competing interests}

The authors declare that they have no competing interests.

Received: 13 April 2020 Accepted: 3 August 2020

Published online: 10 August 2020

\section{References}

1. Cabrera-villalba S, Sanmarti R. Palindromic rheumatism: a reappraisal. Int J Clin Rheumatol. 2013;8(5):569-77.

2. Butbul-Aviel Y, Uziel Y, Hezkelo N, Brik R, Amarilyo G. Is palindromic rheumatism amongst children a benign disease. Pediatr Rheumatol. 2018; 16(1):12.

3. Salehzadeh F. Familial Mediterranean Fever in Iran: A Report from FMF Registration Center. International Journal of Rheumatology Volume 2015, Article ID 912137, 6 pages https://doi.org/10.1155/2015/912137.

4. Infevers. Infevers:an online database for autoinflammatory mutations. Available at https://infevers.umai-montpellier.fr/web/.

5. Ince $E$, Çakar $N$, Tekin $M$, et al. Arthritis in children with familial Mediterranean fever. Rheumatol Int. 2002:21:213 https://doi.org/10.1007/ s00296-001-0168-5.

6. Majeed HA, Rawashdeh M. The clinical patterns of arthritis in children with familial Mediterranean fever. QJM. 1997;90:37-43.

7. Lidar M, Kedem R, Mor A, Levartovesky D, Lanjevitz P, Livneh A. Arthritis as the Sole Episodic Manifestation of Familial Mediterranean fever. J Rheumatol. 2005;32:859-62.

8. Yilmaz S, Erdem H, Tunay S, Torun D, Genc $H$. The presence of MEFV gene mutations in patients with primary osteoarthritis who require surgery. Korean J Intern Med. 2013;28:594-8 https://doi.org/10.3904/kjim. 2013.28.5.594

9. Heller H, Gafni J, Michaeli D, et al. The arthritis of familial Mediterranean fever (FMF). Arthritis Rheum. 1966;9:1-17.

10. Ben-Chetrit E, Peleg H, Aamar S, Heyman S. The spectrum of MEFV clinical presentations-is it familial Mediterranean fever only? Rheumatology. 2009;48: 1455-9. https://doi.org/10.1093/rheumatology/kep296.

11. Rabinovich $E$, Livneh $A$, Langevitz $P$, et al. Severe disease in patients with rheumatoid arthritis carrying a mutation in the Mediterranean fever gene. Ann Rheum Dis. 2005:64:1009-14.

12. Comak E, Dogan CS, Akman S, Koyun M, Gokceoglu AU, Keser I. MEFV gene mutations in Turkish children with juvenile idiopathic arthritis. Eur J Pediatr. 2013;172(8):1061-7. https://doi.org/10.1007/s00431-013-2003-x.

13. Ayaz NA, Ozen S, Bilginer $Y$, et al. MEFV mutations in systemic onset juvenile idiopathic arthritis. Rheumatology (Oxford). 2009;48:23-5.

14. Langevitz P, Livneh A, Zemer D, Shemer J, Pras M. Seronegative spondyloarthropathy in familial Mediterranean fever. Semin Arthritis Rheum. 1997;27:67-72

15. Gershoni-Baruch R, Broza Y, Brik R. Prevalence and significance of mutations in the familial Mediterranean fever gene in Henoch-Schönlein purpura. J Pediatr. 2003;143:658-61.

16. Ozen S, Ben-Chetrit E, Bakkaloglu A, et al. Polyarteritis nodosa in patients with Familial Mediterranean Fever (FMF): a concomitant disease or a feature of FMF? Semin Arthritis Rheum. 2001;30:281-7.

17. Touitou I, Magne X, Molinari N, et al. MEFV mutations in Behçet's disease. Hum Mutat. 2000;16:271-2.
18. Fidder $\mathrm{HH}$, Chowers $\mathrm{Y}$, Lidar $\mathrm{M}$, et al. Crohn disease in patients with familial Mediterranean fever. Medicine (Baltimore). 2002:81:411-6.

19. Booth DR, Lachmann HJ, Gillmore JD, Booth SE, Hawkins PN. Prevalence and significance of the familial Mediterranean fever gene mutation encoding pyrin Q148. Q J Med. 2001;94:527-31.

20. Zhong L, Song H, Wang W, Li J, Ma M. MEFV M694V mutation has a role in susceptibility to ankylosing spondylitis: A meta- analysis. PLoS ONE. 2017; 12(8):e0182967 https://doi.org/10.1371/journal.pone.0182967.

21. Gülhan B, Akkuş A, Özçakar L, Beşbaş N, Özen S. Paediatric rheumatology; Are MEFV mutations susceptibility factors in enthesitis-related arthritis patients in the eastern Mediterranean? Clin Exp Rheumatol. 2014;32(suppl. 84):s160-4.

22. Tunca M, Kirkali G, Soyturk M, Akar S, Pepys MB, Hawkins PN. Acute phase response and evolution of familial Mediterranean fever. Lancet. 1999;353:1415.

23. Touitou I, Kone'-Paut I. Autoinflammatory diseases. Best Pract Res Clin Rheumatol 2008; 22:811-829.

24. Salehzadeh F, Sharghi A, Motayayagheni A, Hosseini Asl S, Mottaghi M, and Sarkhanloo S. MEFV Gene Variant Alleles in Normal Population of Northwest of Iran, Which Is Near to Mediterranean Sea: Genetics Research International Volume 2019, Article ID 6418759, 4 pages https://doi.org/10.1155/2019/ 6418759.

25. Makay B, Gülez N. Long-term follow-up of paediatric MEFV carriers. Clin Rheumatol. 2018;37:1683-7 https://doi.org/10.1007/s10067-017-38833.

\section{Publisher's Note}

Springer Nature remains neutral with regard to jurisdictional claims in published maps and institutional affiliations.
Ready to submit your research? Choose BMC and benefit from:

- fast, convenient online submission

- thorough peer review by experienced researchers in your field

- rapid publication on acceptance

- support for research data, including large and complex data types

- gold Open Access which fosters wider collaboration and increased citations

- maximum visibility for your research: over $100 \mathrm{M}$ website views per year

At BMC, research is always in progress.

Learn more biomedcentral.com/submissions 